Available online at GSC Online Press Directory

GSC Biological and Pharmaceutical Sciences

e-ISSN: 2581-3250, CODEN (USA): GBPSC2

Journal homepage: https://www.gsconlinepress.com/journals/gscbps

(REVIEW ARTICLE)

\title{
Lifestyle modifications: A key to manage diabetes
}

\author{
Ashok B. Giri * , Vishal T. Shinde, Pradip R. Lengare and Dr. Ramdas D. Shinde \\ Shivlingeshwar College of Pharmacy (Pharm.D), Almala Dist.Latur (MH).
}

Publication history: Received on 08 December 2020; revised on 15 December 2020; accepted on 17 December 2020

Article DOI: https://doi.org/10.30574/gscbps.2020.13.3.0405

\begin{abstract}
Diabetes is one of the leading challenges to the health care or'ganization across world. Worldwide, 422 million peoples suffering from diabetes 1 . Diabetes mellitus is a metabolic disorder which is characterized by abnormal metabolism of carbohydrates, fats, protein. The main etiological factors contributes in the development of diabetes are sedentary lifestyle, obesity, intake of junk foods. It is mandatory to manage increased blood sugar level (BSL) to prevent microvascular as well as macrovascular complications.
\end{abstract}

To manage diabetes, metformin and insulin play a key role hence these two medications added in the diabetes pharmacotherapy. Diabetes is not a treatable disease hence we have to maintain weight by doing regular exercise and implementation of dietary modifications.

It is important to maintain the balance of daily calories intake and their utilization by practicing physical activity remain the primary and most effective prevention strategy for diabetes management. A management strategy basically involves promotion of effective weight loss and physical exercise, but it is compulsory to do exercise and follow dietary modifications regularly.

This is a comprehensive review which focuses on lifestyle modifications in diabetes. How lifestyle modification play a key role in the management of both type of diabetes along with pharmacotherapy.

Keywords: Diabetes; Lifestyle modifications; Blood sugar level; Exercise

\section{Introduction}

Diabetes is one of the leading challenges to the health care organization across world. Worldwide, 422 million peoples suffering from diabetes 1 . Diabetes mellitus is a metabolic disorder which is characterized by abnormal metabolism of carbohydrates, fats, protein. The main etiological factors contributes in the development of diabetes are sedentary lifestyle, obesity, intake of junk foods. It is mandatory to manage increased blood sugar level (BSL) to prevent microvascular as well as macrovascular complications 2 .

Diabetic patients may having symptoms such as Increased thirst (Polydipsia), excessive eating or appetite (polyphagia), Frequent urination (polyuria) and also patient may having symptoms of microvascular and macrovascular complications.

\footnotetext{
${ }^{*}$ Corresponding author: Ashok Giri

Student, Shivlingeshwar College of Pharmacy (Pharm.D), Almala Dist.Latur (MH).

Copyright (C) 2020 Author(s) retain the copyright of this article. This article is published under the terms of the Creative Commons Attribution Liscense 4.0.
} 
Diagnosis of DM is majorly based on three criteria viz.: fasting plasma glucose $\geq 126 \mathrm{mg} / \mathrm{dL}$, a 2 -hour value from a 75 -g oral glucose tolerance test $\geq 200 \mathrm{mg} / \mathrm{dL}$, or BSL level of $\geq 200 \mathrm{mg} / \mathrm{dL}$ and patient having symptoms of diabetes viz. polydipsia, polyphagia and polyuria. Diagnosis confirmed by any of the three criteria on a separate day 1 .

Management of DM mainly directed towards attaining normoglycemia, reducing the onset and progression of microvascular and macrovascular complications, intensive therapy for associated cardiovascular risk factors, and improving quality and quantity of life. According to the United Kingdom Prospective Diabetes Study (UKPDS), metformin is only oral hypoglycemic agent which can reduce the risk of total mortality and this drug widely used by doctor to manage BSL. It is mandatory to manage glycemic control to reduce the progression of microvascular and macrovascular complication 2 .

It is important to maintain the balance of daily calories intake and their utilization by practicing physical activity remain the primary and most effective prevention strategy for diabetes management.

A management strategy basically involves promotion of effective weight loss and physical exercise, but it is compulsory to do exercise and follow dietary modifications regularly 3.

Compliance to daily physical activities and dietary changes will reduce the risk of disease progression and duration of long term therapy. Metabolic improvements rapidly vanish with weight regain 4. To prevent risk of increased BSL, long term lifestyle modifications are necessary. It may include daily exercise, balanced diet (Especially fat restriction) and mental health is also one of the main aspects in the management of diabetes and other disease conditions 5 . These things will help to prevent or slow down the complications of type 2 diabetes mellitus. However, the knowledge and practice of healthy lifestyles in many diabetic patients have been inadequate 2 .

This is a review aimed to study the management of diabetes by practice of lifestyle modifications. Also study focuses on positive impact of health education on knowledge attitude, and practices with effectively improved patient glycemic control in diabetes.

\section{Major Lifestyle risk factors to develop disease}

The major lifestyle risk factors that will contribute to develop pathogenesis of metabolic abnormalities are obesity, physical activity, tobacco smoking, alcohol consumption and mental stress. We are actually living in the digital world where we are virtually connected to each other. But we have implemented sedentary lifestyle 1.

Family history, environmental factors (Circumstances such as exposure to a viral illness likely play some role in type 1 DM), autoantibodies formation inside the body, geographical factors are the contributing risk factors to develop type 1 diabetes mellitus among susceptible population. However age (more than 45 years), obesity, race or ethnicity, abnormal cholesterol and triglyceride levels, other disease conditions such as hypertension, polycystic ovarian disease are contributes to develop symptoms of type 2 diabetes mellitus 2 .

If disease will remains undiagnosed that time patient may having various problems such as,

\subsection{Neuropathy}

Increased blood sugar level can damage to nerve or it may not help to nourish the neurons especially in lower limbs. So it will effect on lower limbs and shows variety of symptoms such as tingling, numbness, burning or pain at the tips of the toes or fingers and gradually spreads upward 6.

\subsection{Nephropathy}

Increased BSL may have effect on nephrons; diabetes can damage the units of excretory system. It leads to disturbance in urine formation

Retinopathy: Increased BSL can damage the capillaries of the retina. It may leads to develop various problems such as blindness, conjunctivitis.

\subsection{Cardiovascular disease}

If diabetes is undiagnosed that time patient may suffer from cardiovascular problems including myocardial infraction, Ischemic heart disease and stroke. 


\subsection{Diabetic foot}

Decreased blood flow to the lower limbs and it may causes blisters and cuts. Blisters and cuts converted to serious infection and ultimately require toe, foot or leg amputation.

\subsection{Skin conditions}

Diabetes may causes skin problems which includes bacterial and fungal infection

\subsection{Hearing impairment}

Hearing problems are more common in people with diabetes.

\subsection{Alzheimer's disease}

Increased BSL causes damage to neuron especially brain cell connections. It may leads to develop several neurological problems 2

Depression: Diabetes may have bad impact on psychological status of human being. Hence it can increase severity of depression 5.

\section{Contribution of lifestyle modifications in the management of DM}

The fundamental aspect of diabetic care is to follow lifestyle modifications viz. diabetes self-management education (DSME) system, regular exercise, smoking cessation counseling, and psychosocial care. It is necessary to focus on glycemic control by mean of medical intervention. Patient and health care providers should create a strategy in the management of diabetes from comprehensive diagnosis to discharge of patient from hospital. Post discharge medications and lifestyle modification should provide to the patient. Along with these complications assessment should be considered 78 .

Various studies shown that lifestyle modifications has significant effect in glycemic control, lower HbA1C, lower selfreported weight, improved quality of life and reduced cost of therapy 910 .

An Intensity and duration of physical activity to improve glycemic control is not well defined. However an exercise dose response was reported as physical activities having major role in glycemic control as well as decrease cardiovascular risk. Several cross-sectional and prospective studies show that long duration and high intensity with proper protocol, physical activities are associated with lower prevalence and incidence of obesity and DM 1112.

According to National Health and Nutrition examination survey, implementation of active lifestyle by doing daily exercise at least $60 \mathrm{~min} /$ day and intake of balanced diet can reduce the risk of cardiovascular diseases and diabetes mellitus 13.

In summary, lifestyle modification programs are necessary to maintain metabolic changes in the long period, and such programs should always address both nutritional treatment and physical activity 4 .

\section{Main strategies for living with DM}

\subsection{To educate about risk and complications of DM along with role of lifestyle modifications in the glycemic control}

Diabetes Self-Management Education and Support (DSMES) system is important in the management of diabetes mellitus because patient who have the knowledge about glycemic control strategies are healthier than who do not have. It will save patient's money as well as time and reduces the chances of emergency hospital admission. Also it helps patients to avoid diabetic complication 7.

DSMES System provides following: 
- It make better decision about diabetes

- It work with health care professionals along with patient to manage diabetes

- It gives basic idea about following parameters

- $\quad$ Glycemic range monitoring

- Be active.

- $\quad$ Eat Healthy

- Take your medicine as directed by physician

- $\quad$ Balance mental health with diabetes

- $\quad$ Reduces other health complications 71415.

\subsection{Good Eats}

It is the best key to manage blood sugar level. Good eats means balanced diet that contains proteins, carbohydrates, vitamins and other nutrition in certain amount.

It helps to patient to maintain blood sugar level.

Calorie consumption and utilization should be balanced viz. 1000-1200 kcal/day for overweight women, and 1200$1600 \mathrm{kcal} /$ day for overweight men and heavier for more active women.

For obeys patient diets are designed to create a calorie deficit of 500-1000 kcal/day to promote a weight loss of 0.5$1.0 \mathrm{~kg} /$ week. Several studies show that low carbohydrates diet has direct link to weight reduction 1617.

Dietary recommendations

Table 1 Dietary recommendations as per daily energy consumption and utilization ratio 26

\begin{tabular}{|c|c|c|}
\hline Sr. No. & Type of meal & Energy (Kcal) \\
\hline \multirow{8}{*}{1} & \multicolumn{2}{|l|}{ Breakfast } \\
\hline & Whole-wheat bread,1 med. Slice (1 Bread/Starch) & 70 \\
\hline & Jelly, regular, 2 tsp. ( $1 / 2$ Fruit) & 30 \\
\hline & Cereal, shredded wheat, $1 / 2$ C (1 Bread/Starch) & 104 \\
\hline & Milk, 1\%, 1 C (1 Milk) & 102 \\
\hline & Orange juice, $3 / 4 \mathrm{C}$ (11/2 Fruit) & 78 \\
\hline & Coffee, regular, 1 C (Sugar Free) & 5 \\
\hline & Breakfast total & 389 \\
\hline \multirow[t]{9}{*}{2} & \multicolumn{2}{|l|}{ Lunch } \\
\hline & Whole-wheat bread,2 med. Slices (2 Bread/Starch) & 139 \\
\hline & Lean roast beef, unseasoned, 2oz (2 Lean Protein) & 60 \\
\hline & Lettuce, 1 leaf (1 Vegetable) & 1 \\
\hline & Tomato, 3 med. Slices $(1 / 3$ Fat $)$ & 10 \\
\hline & Mayonnaise, low-calorie, 1 tsp. (1 Fruit) & 15 \\
\hline & Apple, 1 med & 80 \\
\hline & Water, $1 \mathrm{C}$ & 0 \\
\hline & Lunch Total & 305 \\
\hline \multirow[t]{10}{*}{3} & \multicolumn{2}{|l|}{ Dinner } \\
\hline & Salmon, 2 oz. edible (2 Lean Protein) & 103 \\
\hline & Vegetable oil, $1 \frac{11 / 2}{2}$ tsp. & 60 \\
\hline & Baked potato, $3 / 4$ med. (1 Bread/Starch) & 100 \\
\hline & Margarine, 1 tsp. & 34 \\
\hline & Green beans, seasoned, $1 / 2 \mathrm{C}$ (1 Vegetable) & 52 \\
\hline & Carrots, seasoned (1 Vegetable) & 35 \\
\hline & White dinner roll, 1 small (1 Bread/Starch) & 70 \\
\hline & Iced tea, unsweetened, 1 C \& Water, 2 C & 0 \\
\hline & Dinner Total & 454 \\
\hline \multirow[t]{3}{*}{4} & \multicolumn{2}{|l|}{ Snack } \\
\hline & Popcorn, 21/2 C (1 Bread/Starch) & 69 \\
\hline & Margarine, $3 / 4$ tsp. & 30 \\
\hline
\end{tabular}




\begin{tabular}{|l|l|l|}
\hline & Snack Total & 99 \\
\hline 5 & Grand Total & 1247 \\
\hline
\end{tabular}

\subsection{Get active- Be energetic}

Being more active is an essential tool for diabetes. It increases sensitivity of insulin indirectly. It also has a vital role in the prevention of diabetic complications viz. retinopathy, neuropathy, nephropathy and cardiovascular comorbidities. Daily Exercise is necessary for at least $60 \mathrm{~min} 18$ 6. It should increase slowly day by day starting from easy exercise to avoid chances of hypoglycemia; if heavy exercise performed by patient. If patient choose brisk walking as the preferred activity then patient should be instructed by counselor to add 500 steps at 3-day intervals to a target value of 10,00012,000 steps/day 19. While some patients may prefer aerobic exercise, resistance exercises. (Strength Training is contraindicated in the presence of comorbidities viz. hypertension, cardiovascular diseases). Moderate-intensity physical activities may include walking briskly, doing housework, mowing the lawn, dancing, and swimming, bicycling and playing sports. These activities may increase your muscle strength as well as you became mentally fit.

Exercise Recommendations

Table 2 Exercise Recommendations as per age groups. It explains type of exercise allowed to do in respective age group 199

\begin{tabular}{|c|c|c|c|c|}
\hline Sr. No & Age Group & Type of Diabetes & Exercise pattern & Duration \\
\hline 1 & $\begin{array}{lr}\text { Children } & (2-12 \\
\text { years }) & \text { and } \\
\text { adolescents(12-16 } \\
\text { years) }\end{array}$ & $\begin{array}{l}\text { T1DM, } \\
\text { prediabetes }\end{array}$ & $\begin{array}{l}\text { moderate- or vigorous intensity } \\
\text { aerobic activity, with vigorous } \\
\text { muscle-strengthening and bone- } \\
\text { strengthening activities }\end{array}$ & $\begin{array}{l}\text { At least } 60 \mathrm{~min} / \text { day } \\
(3 \text { days/week) }\end{array}$ \\
\hline 2 & Adult(18-35 years) & $\begin{array}{l}\text { T1DM, } \\
\text { prediabetes }\end{array}$ & $\begin{array}{l}\text { Moderate to vigorous intensity } \\
\text { physical activity } \\
\text { Prolonged sitting should be } \\
\text { interrupted every } 30 \mathrm{~min} \text { for } \\
\text { maintaining BSL }\end{array}$ & $\begin{array}{l}\text { At least } 150 \\
\text { min/week } \\
\text { (with no more than } 2 \\
\text { consecutive days } \\
\text { without activity) }\end{array}$ \\
\hline 3 & Adult(18-35 years) & T1DM, T2DM & $\begin{array}{l}\text { resistance exercise/ Strengthening } \\
\text { exercise }\end{array}$ & 2-3 sessions/week \\
\hline 4 & $\begin{array}{l}\text { Middle aged Person } \\
\text { (36-55 years), Elder } \\
\text { Person }(\geq 55 \text { years })\end{array}$ & T1DM, T2DM & $\begin{array}{l}\text { Flexibility training, balance } \\
\text { Training, Yoga- }\end{array}$ & $\begin{array}{l}\text { At least } 30 \mathrm{~min} / \text { day } \\
(2 / 3 \text { times/week })\end{array}$ \\
\hline
\end{tabular}

\subsection{Healthy weight}

We already know that obesity is related to development of cardiac comorbidities as well as diabetes. So weight assessment is necessary to avoid such complications. If increase in weight simultaneously in diabetic patient, may develop cardiac comorbidities 20.

A parameter which describes proportion of weight to height is called as body mass index (BMI). BMI can be an indicator of high fatness.

BMI range should always in between 18.5 - 24.9 for healthy life. Following table describes BMI range as per weight status

Table 3 Body mass index (BMI) as per weight status 20

\begin{tabular}{|l|l|l|}
\hline Sr. No & Type & BMI range \\
\hline 1 & Underweight & $\leq 18.5$ \\
\hline 2 & Normal/Healthy weight & $18.5-24.9$ \\
\hline
\end{tabular}




\begin{tabular}{|l|l|l|}
\hline 3 & overweight & $25-29.9$ \\
\hline 4 & obesity & $\geq 30$ \\
\hline
\end{tabular}

Healthy food and daily physical activities are essential tools for management of weight and thereby it decreases risk of diabetic complications 21

\subsection{Glycemic control}

Diabetic management must include blood sugar level assessment. It is important to keep BSL in normal range as much as possible to prevent complications. Normal BSL can improve quality of life of a patient. Continuous glucose monitoring will helps to stay BSL in normal range. BSL assessment can be done by using glucometer. To check BSL, take small sample of blood from fingertip and drop it on glucometer strip. For more concise information patient should follow directions which is available in leaflet of glucometer.

Along with daily monitoring of BSL, $\mathrm{HbA1C}$ is also taken every 6 months for accurate monitoring of glycemic range. Normal ranges are as fasting BSL should be in between $80-130 \mathrm{mg} / \mathrm{dl}$ ( 4.0 to $5.4 \mathrm{mmol} / \mathrm{L}$ ); postprandial BSL up to 200 $\mathrm{mg} / \mathrm{dl}$ (up to $7.8 \mathrm{mmol} / \mathrm{L}$ ).

Diabetic patient who take daily insulin and oral hypoglycemic agents having high risk of hypoglycemia hence whenever brisk walking started at morning, it is necessary to keep sugary chocolates in a pocket 22.

\subsection{Managing sick days \& emergency preparedness}

Every diabetic patient trying to keep BSL in normal ranges as much as possible but they can get sick. It is essential to be ready before getting sick with all aspects. Patient should keep all the necessary medicines. Make sure patient have insulin, other diabetic medications along with enough food for several weeks especially in this pandemic era.

Follow these steps whenever patient getting sick

- $\quad$ Monitor BSL range every 4 hours and check glycemic status

- $\quad$ Take insulin and other diabetic medications as usual

- $\quad$ Drink plenty of water and other fluids.

- $\quad$ Monitor BMI regularly

- $\quad$ Check your temperature every morning and evening. A fever may be a sign of infection.

- If patient having trouble in breathing and $\mathrm{BSL} \leq 60 \mathrm{mg} / \mathrm{dl}$ then immediately visit to the nearest hospital 23.

\subsection{Diabetes and mental Health}

Diabetic patient is always in depression state because of fluctuation in BSL at certain time. Fluctuation in BSL can create mental problems such as fatigue, stress and especially causes diabetes distress. Diabetes distress means stress, depression and anxiety due to diabetes 245 .

To maintain good metal state in diabetes, we have to manage our stress by listening music and doing meditation regularly, Along with this, Cognitive-behavioral therapy (CBT), Family therapy, \& Dialectical- behavioral therapy (DBT) are the basic tools to manage diabetic distress. CBT means we have to develop belief about our healthy life. Family therapy includes helps to family member to solve their issues and discussion is a part of family therapy. And DBT mainly focuses on teaching skills.

In addition to the therapies, some antianxiety and antidepressant drug helps to relieve symptom. When patient has high level of mental symptoms then visit to psychiatry clinic as soon as possible 25.

\section{Lifestyle modifications with pharmacotherapy}

Doing lifestyle modifications along with pharmacotherapy surely manage the disease well. Several studies compare the effect of lifestyle modification and pharmacotherapy on disease management. These data show that lifestyle modification and pharmacotherapy are equivalent when used separately, but additive when used in combination 2627 . 


\section{Future scope of diabetic management strategies}

Nowadays, diabetic management is focuses on medication therapy viz. insulin and other oral hypoglycemic agents. But it has less potential so we have to go with lifestyle modification along with pharmacotherapy. Understanding of the biochemical and molecular basis of diabetes mellitus will be one of the future aspects to learn more about diabetes. Surely it will helps in the management of diabetes mellitus. Diabetes mellitus is managed by doing regular exercise and implementing dietary modifications will be helpful in future prospective 21 . This type of thinking will reduces the deaths due to diabetic complications.

The immunological concerns underlying gene therapy can also be addressed by the current advances in molecular biology. However, irrespective of all these concerns, it is imperative to always that the merits of gene therapy of diabetes exceed the demerits and present advantages as compared with conventional treatment before this approach could gain widespread acceptance in general medical practice.

\section{Conclusion}

A lifestyle change is a main aspect in the management of diabetes. Various health care providers follow various guidelines that mainly depend on lifestyle modifications. Several data show that doing daily exercise (at least 60 $\mathrm{min}$ /day) and follow dietary modifications can prevent the complications of diabetes. It also helps to keep mental health along with physical health. Meal replacement, combining lifestyle modifications with pharmacotherapy, setting daily exercise goal improves health status.

More research is needed to create impact of lifestyle modification on diabetic treatment. One day will came when a patient manage their BSL by using lifestyle modification tools that day became a marvel in the world of diabetes.

\section{Compliance with ethical standards}

\section{Acknowledgments}

The Author gratefully acknowledges the continuous support and guidance from Mr. Vishweshwar Dharashive Sir (Principal at Shivlingeshwar College of pharmacy, Latur, India), Dr. Chavan ma'am, Mr. Dinesh Gujrathi Sir, Mr. Sameer Shafi Sir, and Mr. Ladde Sir.

\section{Disclosure of conflict of interest}

All Authors contributed equally and declared that they have no conflict of interest.

\section{References}

[1] International Diabetes Federation. 2019.

[2] Joseph T. Dipiro RLTGCYGRMBGWLMP. Pharmacotherapy: A pathophysiologic approach. 7th ed. New Delhi: McGraw Hill Medical Publication.

[3] Magkos F YMCJMC. Management of the metabolic syndrome and type 2 diabetes through lifestyle modification. National Library of Medicine. 2009; 223-256.

[4] Jakicic JM OA. Physical activity considerations for the treatment and prevention of obesity. Am J Clin Nutr. 2005; 82(Supplement 1): 226S-229S.

[5] Anderson BJ MA. Psychological issues in the treatment of diabetes. In: RS IB, ed. Joslin's Diabetes Deskbook. 2nd ed. Boston. 2007.

[6] US Department of Health and Human Services US. Dietary guidelines for Americans. 6th ed. Washington DC: US Government Printing Office. 2005.

[7] Powers MA, BJCMea. Diabetes Self-management Education and support in Type 2 Diabetes. In American Association of Diabetes Educators AoNaD, ed

[8] Linda Haas dMM. National Standards for Diabetes self-management education and support. Diabetes Care. January 2014; Supplement 1: 44-53. 
[9] Aslak Steinsbekk 1, *, LRMLMBRaAF. Group based diabetes self-management education compared to routine treatment for people with type 2 diabetes mellitus. BMC Health Services Research. 2012; 12: 1-19.

[10] Deakin T MCCJWR. Group based training for self-management strategies in people with type 2 diabetes mellitus. Cochrane Database Syst Rev. April 2005.

[11] Carroll S DM. What is the relationship between exercise and metabolic abnormalities? Review of the metabolic syndrome. Sports Med. review of the metabolic syndrome. Sports Med.; 34(6): 371-418.

[12] Katzmarzyk PT HK. The role of physical activity and fitness in the prevention and treatment of metabolic syndrome. Curr Cardiovasc Risk Rep. 2007; 1(3): 228-236.

[13] Sisson SB CSCTTLCJWKP. Accelerometer-determined steps/day and metabolic syndrome. Am J Prev Med. 2010; 38(6): 575-582.

[14] Bandura A. Social foundations of thought and action: A social cognitive theory. APA PsycInfo. 1986.

[15] Wilson GT ST. The transtheoretical model and motivational interviewing in the treatment of eating and weight disorders. Clinical Psychology Review. 2004; 24(3): 361-378.

[16] Foster GD WHHJea. A randomized trial of a low-carbohydrate diet for obesity. The New England Journal of Medicine. May 2003; 348(21): 2082-2090.

[17] Samaha FF INSPea. A low-carbohydrate as compared with a low-fat diet in severe obesity. The new England Journal of Medicine. 2003; 348(21): 2074-2081.

[18] Wing RR, VEJJPBLW. Lifestyle intervention in overweight individuals with a family history of diabetes. American Diabetes Association, Diabetic Care. 1998; 21(3): 350-359.

[19] Park S PHTFea. Year-long physical activity and metabolic syndrome in older Japanese adults: cross-sectional data. J Gerontol A Biol Sci Med. 2008; 63(10): 1119-1123.

[20] Greenway FL FKPRea. Effect of naltrexone plus bupropion on weight loss in overweight and obese adults (CORI): a multicenter, randomized, double-blind, placebo-controlled, phase 3 trial. Lancet. 2010; 376(9741): $595-605$.

[21] Perry MG SSJCJ. Strategies for improving maintenance of weight loss. Toward a continuous care model of obesity management. ADA, Diabetes Care. 1993; 16(1): 200-209.

[22] Nene EA JTUGKA. Management of type 2 diabetes: evolving strategies for the treatment of patients with type 2 diabetes. Division of Endocrinology, Diabetes and Metabolism, Department of Medicine, The University of Tennessee Health Science Center, Memphis, TN 38163, USA. 2011; 60: 1-23.

[23] Association AD.When You're Sick." Diabetes Spectrum/Patient Information: "Be Prepared: Sick Day Management. 2002.

[24] Egede LE ZDSK. Comorbid depression is associated with increased health care use and expenditures in individuals with diabetes. 2002; 3: 464-470.

[25] Katon W FCC. Treatment of depression in patients with diabetes: efficacy, effectiveness and maintenance trials and new service models. In: Katon W MMS, ed. Depression and Diabetes: John Wiley \& Sons. 2010.

[26] Torgerson JS HJBMSL. XENical in the prevention of diabetes in obese subjects (XENDOS) study: a randomized study of orlistat as an adjunct to lifestyle changes for the prevention of type 2 diabetes in obese patients. American Diabetes Association: Diabetes Care. 2004; 27(1): 155-161.

[27] U.S. Food and Drug Administration. Early Communication About an Ongoing Safety Review Orlistat (Marketed as Alli and Xenical). 2009.

[28] Miller WR RS. Motivational Interviewing. 2002. 